\title{
New Media, Urban Marginals and Gerontocracy in India: A Study of Older Adults in Kolkata
}

\author{
Dr. Debarati Dhar \\ Assistant Professor, School of Communications, XIM University, Bhubaneswar, India. \\ Email: dhardebarati@gmail.com
}

\begin{abstract}
My paper seeks to explore the linkage between new media and the Urban Marginals with special emphasis on ageing population in Kolkata. Conventional use of media for ageing has made the aged population a passive victim to be duped by the media messages. Given the structural locations and positions, mass media is of no use where the considerations are for younger populations. Although ageing population may be a marginal category keeping in view the larger media ecology, new media provides the potential to the aged population to be inclusive of urban governance provided they have access and availability. With the help of substantive details, my paper would seek to address the idea of 'precarity' associated with aged population and their way of coping with such precarity with the help of new media in Kolkata. This paper would provide a select reading of samples (qualitative data) from different regions of Kolkata. Through substantive details my paper would provide insights about a vulnerable population, otherwise, neglected in the making of urban governance.
\end{abstract}

Keywords: New Media, ageing population, older adults, urban governance, mass media, Kolkata.

\section{Introduction}

In the present century, one of the most signifying characteristics of India is its increasing greying population. With the rapid change in the socio-economic and demographic situation across the nation, living conditions for the older adults have changed considerably. Quite significantly, older adults need family support and care. However, the concept of traditional joint family has been taken over with increasing popularity of nuclear family system because of continuous migration leaving the older people to fend for themselves. They are being constantly marginalized and isolated especially in urban areas. As a result, older adults face a number of problems ranging from social isolation to depression and lack of socialization. Despite the growing share in population, aged people are not getting the due attention in the society.

Most of the existing studies on information communication technologies identify some of the key critical questions such as the accessibility factor and i.e. means of accessibility, affordability, purpose of using the new media tools and information resources for the aged population in the larger social context. What is significant to note at this juncture is how the older

This Open Access article is published under a Creative Commons Attribution Non-Commercial 4.0 International License (http://creativecommons.org/licenses/by-nc/4.0/), which permits non-commercial re-use, distribution, and reproduction in any medium, provided the original work is properly cited. For citation use the DOI. For commercial re-use, please contact editor@rupkatha.com. 
adults are coping with the issue of digital literacy and how new media can provide them with a new direction in contributing more actively into the labour market. Empowering the aged people is vital so that they can age in a healthy way and can actively contribute to the labour industry. It is also important because that helps in coping with the possible demographic challenge creating a new direction towards reducing ageism and productive and active ageing with an extended working life. It will also help in addressing a global concern of the outcome of social inequality within the changing modern society and across life course of an individual. Somehow, little thought has been given to the work quality, precarity of working life in the later years.

While considering ageing and new media, there are several intersecting societal trends in place across the country and globe. For inclusive growth, what matters is addressing the multifaceted nature of disparities and their effects on diverse age groups. Learning a new skill or technology can be an unnerving task for people of any age, but this is specifically true in case of senior citizens. Through a select reading of samples from different regions of Kolkata, the main research questions this paper tries to explore are: what new media usage does the older people have in their daily lives, what are their attitudes and perceptions towards the new media and how are they coping with precarious ageing with the help of new media? Most of the respondents interviewed were retired and some of them were engaged in part time vocational works. The socio-economic profile of the respondents was found to be stable.

\section{New Media and Precarious Ageing population}

Some of the common notions affecting ageing are non-economic offerings of the aged people to the society, vulnerability and the impacts of ever increasing precarious life courses, and the various extents of inequality. These factors indicate towards a precarious later life. The report of the 'International Labour Organisation's World Social Protection Report'1 shows that around " 49 per cent of all people over pensionable age do not receive a pension and for many who do, pension levels might leave them below the poverty lines". The term aged or aging people is applied to different age groups and can vary from 60 years of age and upwards. Considering the present scenario of increased life expectancy and the age difference with almost 35 years between generations, it is important to understand and recognize that the range of life experience, learning ability and knowledge will vary extensively. It is equally important to understand that sequential age is not similar as that the biological age. To put in simpler words it can be said that a fit and vigorous 75 year-old may be chronologically old but physically much younger and healthier than a 65 year-old with prolonged health and movement issues. So, all these points need to be understood and recognized properly when thinking about what is meant by 'older people'. The term aged is not very precise as the ageing experience reveals class and gender differences.

The present deliberation on precarity actually does not encompass the older adults. The increased life expectancy has given rise to the question over the accessibility and nature of work

\footnotetext{
${ }^{1}$ ILO World Social Protection Report. Building economic recovery, inclusive development and social justice, 2014/15. Retrieved from http://www.ilo.org/global/research/global-reports/world-social -securityreport/2014/WCMS_245201/lang-en/index.html
} 
that are available for the ageing people considering that people of this age group come under the 'additional pool of labour'. Apart from that, the changing family structure, insufficient and unreasonable support and care services are crucial results of this changing setting in advanced economies. In urban areas the idea of nuclear families is observed as the present trend due to children shifting to other places for better job as well as educational opportunities because of which the joint family structure and intergenerational ties is weakening. "Nuclear families are characterized by independence, individuality and desire for privacy and precisely these are some of the factors that are replacing the joint family that emphasizes deference to age and authority" (Shettar, 2013).

The present paper is an attempt to highlight the potential and scope of new media tools in addressing to some of the common problems of the aged people like loneliness and depression. It is easier to say that smart phones and computers and internet can really provide communication support and emotional outlet to the aged people especially those who have mobility issues and whose children have moved to other place for better job opportunities but at the same time it is hard to ignore the possibly negative significances of new media use in older age. There is abundance of information online and with it comes the possibilities of falling into the trap of online fraudulence via the virtual communities. Aged people are a vulnerable section to online deceitfulness however with sufficient initial training and proper understanding such treachery can be avoided making the online communication experience a pleasant and enriching one.

Through substantive details an attempt has been made to recognize the connections between precarious living situations and access to new media technologies. Despite of the fact that internet and mobile phones specifically are easily available and quite accessible in almost all households it was worth realizing that the socio-economical realities of the respondents had an influence on the uses of technologies contradictory of what is being considered as their potential of becoming digital commons. It also needs to be noted that there may be availability of new media tools for the aged to reinforce their earning and vocational tools but as with increasing age most of the elderly are grasping with physical and psychological impairments. One of the vital elements observed among the aged people was the factor that determined the interest of using the new media was finding a reason to use the Internet and infuse it for social engagement and earning process. Engagement reasons were mostly personal in nature, like for instance one elderly man intermittently looked for YouTube videos on physical exercise that would help him improve the back pain. Daily management of online accounts was however found to be a task not preferred by the elderly people.

The scope of my study was the city of Kolkata (Kolkata Municipal Corporation), which is the capital city of West Bengal, a state in the eastern part of India. For this particular study, interview method was applied to a selective sample of 80 respondents (selected randomly out of the total respondents of the doctoral study undertaken in the same field) who were part of the larger doctoral study. Majority of the respondents interviewed for this study have their children settled abroad or in other cities of the country and the new media tools remain the only source of communication for them. All the respondents are economically affluent and they own landline and mobile phones, internet connections and other electronic devices at home. However, the online usage is very limited for the aged respondents in most of the cases and is basically confined to interacting with the children staying away. Online experiences shared by the aged people have 
provided great understandings on the way older adults are making use of the new media as well as the network communities to fulfill their different needs. Contradictorily, in this technology age virtual interaction and communication is still not prevalent among the older adults because of certain prevalent factors such as low penetration levels of technology, lack of access, dependency on children, lack of financial independence and ultimately low digital literacy. There are mainly two types of new media users among the aged people, firstly old people with a decent level of digital understanding and with adequate financial back up who are also intended in learning and familiarizing with the new technologies. Interestingly, this group of user is not only making the best use of the online mode for sharing of information by emails and through social networking sites and gathering information through search engines, but at the same time also using it creatively for live chats, group discussions or talks, sharing snaps or videos, etc. This group of users is capable of navigating through the virtual communities themselves. However, there is the secondary users group which is not very proficient with the virtual language and operations and they can only use the new media and communicate via the internet with the help and support of their children, relatives and friends.

\section{New Media Interventions for the Aged}

Within gerontology, impetus has been accumulating to create a critical social agenda for the varying socio-economic demography. Unlike their younger counterparts the elderly use the social media in a very sensitive way as they are concerned about the privacy issues and basically use the social networking tools to connect with like-minded persons. Apart from social networking, the aged people use the new media and internet for extracting health information and to give and provide support with others who are experiencing the same ageing challenges. The aged people are adapting to the new media because they have realized that others in their age group are gradually going online and have creatively used it to start discussion forums on issues related to life and health relevant to them. The new media offers them the initial support and comfort on issues such as depression, dementia, anxiety or diabetes within the convenience of their homes. As pointed out by Kamiel (2006), "the elderly use these tools to bridge the geographic gap between them and their loved ones living far away and as a way to re-connect with friends from a far off time. Previous research shows that the internet has become an important portal for reducing isolation, loneliness and other depressive symptoms among the older adults".

Apart from the communication aspect, elderly respondents emphasized on the informational and educational facets of the internet and added that they use it in an encyclopaedic way for getting any information right from government sites for latest schemes to financial banking sites. Many of the older adults have discovered the online travelogue and some of them have shared a different experience of exploring the unseen places across the globe through digital travel pieces. An elderly lady of around 67 years, who lives alone and have retired from a teaching job few years back shared how she had enjoyed travelling different places during her earlier days. She confesses that because of increasing pain and failing health she could not travel anymore which she misses immensely. However, the digital travelogue lets her explore the many unseen places across the world and she feels blessed that she has learnt to use the computers and internet. Just like her, this gateway to the outside world is vital to those who have become 
completely homebound. In a similar context, May (2015), noted that senior travellers not only search for information but also increasingly share information through social networking sites. Older adults, just like their younger counterparts, heavily depend on various travel websites for information and also supplement their information search through the social media sites.

The older generation is of the opinion that social networking sites and applications serve them quite well. The aged respondents have discovered that video chatting is a great way to bring children, friends and folks from distant destinations right into their homes. One elderly woman reported feeling "invigorated" after she started using the smart phone and internet. She explained that the social media has become a major part of her life and it has helped her from slipping into a slower pace. Her grandchildren insists her to upload pictures and as a result of which she admits that she finds herself caring more about her appearance and staying fit. As noted by Smith, (2014), once the elderly people join the virtual world, digital technology becomes an integral part of their daily existence. During the survey, this was observed that most of the senior citizens who became internet users have been found visiting the web world quite frequently. Some of them remain 'online' most of the time and feel that there are so many activities to do online that even 10 to 12 hours a day appears less. Such older internet users have strong positive attitudes and perceptions about the advantages of online information that can be obtained instantly benefitting their personal lives. Older adults who are active internet users are of the opinion that people without new media or internet access are depriving themselves of the benefits of all the online information. They also opined that the internet makes it much easier to access information at any time, which was impossible in earlier times.

The idea of spiral of silence theory, which states that people have this fear that holding views contrary to the dominant views in the media might make them isolated or rejected and prefer to keep those views to themselves. This logic can be applied in the context of older adults and their adaptation to new media because what is gathered from the literature is that lesser older adults were found to be comfortable in using the new media. As with increasing age older adults tend to keep their attitudes to themselves because of factors like illness or loss of companion or acquaintances. The sense of isolation or separation makes them a vulnerable group. As in the spiral of silence theory, the media tend to present many sides of an issue that further encourages people with opposing views to keep quiet and this theory presents an excellent example of the cumulative effects of media. Spiral of silence theory argues that 'media can have a powerful influence on everyday talk of the people'. Older adults unlike their younger counterparts often tend to feel left out as they do fall into the vicinity of usage of new media.

Many people think that new media is an exclusive domain for the younger generation though this notion is not entirely correct. Many of the elderly people have enthusiastically adopted the new media to keep up with the times as well as their old connections and family members. The survey results show that the grandparents are becoming proficient in social networking sites and liking it as they can directly connect with their children and especially grandchildren. In fact, in some cases the grandchildren are the source of inspiration and initial training for the aged users. New media gives them the much needed healthy emotional outlet. From the responses, it is evident that the aged generation uses the new media tools to bridge the physical distance that exists between them and their loved ones and it is the most convenient way to connection or reconnection. Apart from the socializing aspect older adults are of the opinion that information and 
education aspects related to financial and health issues are another major draw for them. Internet has become more of a need to them. From depression, diabetes to dementia, the elders can get and give support and information within the comfort and convenience of their homes.

In families where ageing couples are living alone away from their children, new media are in much frequent use comparatively. These couple had to overcome the initial fear and inhibitions as they have to get connected with their children. One female respondent of 65 years of age recounted how she started exploring the possibilities of new media when her only son decided to shift to Germany few years back around 2009. She explored it systematically with the support of relatives and other family members. She recalls it was not easy for her initially and how she dreaded the thought of touching the laptop. However, after months she was relieved once the information was at her disposal and she thoroughly practiced it every day. She could talk and as well as see her son who later settled there. She had visited her son few times during all these years and she also has a grandson now. She happily reveals that now she enjoys using the smart phone and laptop because the biggest inspiration is her grandson. She shares her happy moments that she could experience through new media. She could see videos and pictures of the newly built house of her son; or photos of her grandson, etc.

Another elderly couple in the age group of 65-70 years shares that how they were reluctant to idea of their elder son moving abroad. Initially they were sad and remained silent for several days at a row and months. However, they really are grateful to the social networking sites as it had enabled them to stay in touch with their son. Mentioning about the skills required for adapting to new media, the couple shares that as the husband had a fair knowledge of using computers, it never created any hindrance in their connectivity with their son. The wife though not very comfortable in using the computers or smart phones says she doesn't really feel the need to learn it separately as her husband is with her. Similarly, while interviewing several other elderly couples, it was observed that men generally dominate the computer and mobile phone operation while women play a supportive role.

\section{Observations \& Discussions}

The significant observation made here is that precarity is a social phenomenon; it is the product of policies with a possibility of change. It is not rooted in the body biologically, though it might have significances that can both intensify the possibility to handle ill health in later life. As explored by Biggs, (2014) a realistic approach to the question of a long healthy life lies in connection and intergenerational relationships. Besides requiring social contribution, generational empathy and connectivity tools and an early stoppage of precarious lives can be the solution of sorted ageing urban marginals. Facilitation of new media roles leading to larger attention to inter-generational linking and witnessing new ways of releasing age-specific possibilities were also observed during the field study.

Another most significant observation made was that the older adults who are using the new media and social networking sites reported feeling less lonely because of the immediate connects they could make with their children, relatives, friends and folks with common interests. Results from the interviews show that aged people in the city go online predominantly with their 
mobile phones (smart phones). Aged people were found to be outward-looking and inclined towards initiating a wider network of social relationships. It is not always that the older adults have been comfortable with the idea of using smart phones and laptops. A significant majority of the aged people interviewed admitted that they needed assistance initially for using the new digital devices. There were many elderly who have critical health issues, which make it quite difficult to use the new media technologies.

Majority of the respondents admitted to be self-assessed beginners and had very little or average level of technological skills. The senior respondents who do not use the new media technologies and internet were asked the question whether they feel that lack of access to internet is disadvantageous or not. A mixed set of responses was derived with half of these non-users agreeing with the fact that they are lacking the advantages and information offered by the internet while some elderly non-users disagreeing that they are actually not missing out any advantage because they feel face to face interpersonal communication cannot be replaced with the video chatting and for the purpose of obtaining information newspaper and television is enough. Some of them literally had no interest in adapting to a new form of technology at this age as they feel it is way too difficult for them. They are of the opinion that with the increasing age there is certain decline in memory and the physical problems make it difficult to understand the complexities of new media, which according to them should be made more aged-friendly. However, they also believe that proper training programme could help in minimizing the initial inhibitions and some of the obstacles that discourage the aged people from using the new media resources that can largely benefit them. Zickuhr \& Madden (2012), in their study also noted a similar aspect that once the older adults' are given the tools and initial training required to start using the internet, gradually they become avid users of the new media technology. According to this study computer mediated communication and email remained the most preferred medium of communication among the older adults (Zickuhr \& Madden, 2012). For older adults, adapting to new media technology was perhaps most notable in the arenas of social connection and expression of progressive ideas. In brief, new media in particular can help in the promotion of models of dynamic and productive ageing and of an economic outline of genuine social engagement to work availability.

\section{Conclusion}

In the later life of an individual the likelihood of a gradually precarious existence would be aggravated by a number of factors such as an expansion of the constitutional superannuation age, availability of appropriate work for the elderly people, etc. These trends when considered together direct towards an indefinite world where the outlook of a longer life becomes ever more difficult to predict. At the same time, it leads to a number of pertinent questions for further gerontological research and policymaking. Questions that arise out of the new media and precarious ageing debate are what might be the growing effects of present socio-economic drifts and, by inference, what might be the probable preventive actions that can be taken earlier in the life course? How to enhance communication in the inter-generational context and what sort of culture would best meet the requirements of old age and deprivation? 
New media and internet have the potential to support aged people in a number of ways like helping them in staying connected to their near and dear ones through chat, call or email. For some reason, when new media users are discussed, it is always about the celebration of the young generation. However, silver surfers though might appear reluctant initially and often require assistance to use the new media and internet yet this is the group who perform better cognitively and experience improved mental and physical well-being. New media technology is continually evolving and as a result the existing forms of technology will constantly be replaced or converged with more modernized versions. There are differences of attitudes and perceptions regarding the new media and internet among the aged people. Although some aged people still think of technologies such as televisions and the basic mobile phones to be comparatively new, there are others who perceive those to be the technologies of the past. It is very unfortunate that the elderly are frequently considered as mentally and physically weak and less competent, resilient to change and generally less flexible or adjustable to new situations. So, in such a scenario it becomes even more significant to break these kinds of stereotypes and consider ways in which older adults could be encouraged to use the new media more and more for their overall physical and emotional wellbeing. New media has the potential to bridge this digital divide in terms of adequacy of access and capability of use and knowledge among the senior citizens.

\section{Acknowledgement}

This paper is an outcome of the larger Doctoral study. I would like to thank Prof. Biswajit Das, Founding Director, Centre for Culture, Media \&amp; Governance, Jamia Millia Islamia, New Delhi for his most constructive criticism and witty comments on the paper. His scrutiny and suggestions were extremely valuable and insightful for finalising the paper.

\section{References}

Bate, J. (1999). Shakespeare and original genius. In P. Murray (Ed.), Genius - The History of an Idea. New York: Basil Blackwell. 76-97

Baars, J., Dohmen, J.,Grenier, A., Phillipson, C. (2013). Ageing,Meaning and Social Structure:Connecting Critical and Humanistic Gerontology. Bristol: Policy Press.

Bowling Green State University. (2015, April 29). New technology, tablets still a struggle for older generations. ScienceDaily. Retrieved March 17, 2017 from www.sciencedaily.com/releases/2015/04/150429100917.htm

Biggs, S. (2014). Adapting to an ageing society: The need for cultural change. Policy Quarterly; 10:12-16.

Czaja, S. J., Charness, N., Fisk, A., Hertzog, C., Nair, S., Rogers, W., et al. (2006). Factors Predicting the Use of Technology: Findings From the Center for Research and Education on Aging and Technology Enhancement (CREATE). Psychology \& Ageing, Volume 21, Issue 2, 333-352.

Czaja, S. J., \& Lee, C. (2003). The impact of the internet on older adults. In N. Charness, \& K. Warner Schaie (Eds.), Impact of technology on successful aging (pp. 113-133). New York, NY: Springer Publishing Company, Inc.

Dhar, D. (2018). Media, Sociality, and Aging Process: A Study of Aging Process through New Media in Select Areas of Kolkata. Asian Journal for Public Opinion Research, 204-227. 
9 | New Media, Urban Marginals and Gerontocracy in India: A Study of Older Adults in Kolkata

Dhar, D. (2017). New Media use in Everyday Life of Aged People: A Study in Kolkata . Journal of Content, Community \& Communication, 5(3), 38-42.

Gurumurthy, K. (1998). The Aged in India. New Delhi: Reliance Publishing House.

Kamiel, A. (2016, July 3). A Hot Trend: The Internet, Social Media \& The Elderly. Retrieved March 15, 2017, from The Huffington Post: http://www.huffingtonpost.com/anita-kamiel-rn-mps/older-people-socialmedia_b_9191178.html

Kinney, J.M., Kart, C.S., Murdoch, L.D. et al. (2003). Ageing International, 28: 295. doi:10.1007/s12126-0021009-x

Livingstone, S., \& Bovill, M. (2001). Children and their Changing Media Environment: A European Comparative Study. Hillsdale, N.J: Lawrence Erlbaum Associates.

Madden, M. (2010, August 27). Older Adults and Social Media. Retrieved December 14, 2016, from PewResearchCenter: http://www.pewinternet.org/2010/08/27/older-adults-and-social-media/

May, K. (2015, October 1). Understanding the older generation and its tech-savvy relationship with travel. Retrieved March 14, 2017, from Tnooz Reports: https://www.tnooz.com/article/understanding-theolder-generation-and-its-tech-savvy-relationship-with-travel/

Mitzner, T. L., Boron, J. B., Fausset, C. B., Adams, A. E., Charness, N., Czaja, S. J., \& Sharit, J. (2010). Older adults talk technology: Technology usage and attitudes. Computers in Human Behavior, 26, 17101721. doi:10.1016/j.chb.2010.06.020

Morris, S. (2014, December 12). Study finds social media use beneficial to overall health of elderly. Retrieved March 16, 2017, from The Guardian: https://www.theguardian.com/media/2014/dec/12/study-finds-social-media-skype-facebook-usebeneficial-overall-health-elderly

Olson, K. E., O'Brien, M. A., Rogers, W. A., \& Charness, N. (2011). Diffusion of technology: Frequency of use for younger and older adults. Ageing International, 36: 123-145. doi: 10.1007/s12126-010-9077-9

Rogers, E. M. (2003). Diffusion of innovations. New York, NY: Free Press.

Selwyn, N. (2004). The Information aged: A Qualitative study of older adults' use of information and communication technology. Journal of Ageing Studies.

Sen, S. (2015, October 27). Kolkata is ageing faster than other metros. Retrieved March 12, 2017, from The Times of India, City: http://timesofindia.indiatimes.com/city/kolkata/Kolkata-is-ageing-faster-thanother-metros/articleshow/49546289.cms

Shettar, S. (2013, August 1). Problems of Aged in Changing Indian Scenario. Retrieved March 9, 2017, from Yojana: http://yojana.gov.in/problems-of-aged.asp

Smith, A. (2014, April 3). Older Adults and Technology Use. Retrieved March 2, 2017, from Pew Research Center: http://www.pewinternet.org/files/2014/04/PIP_Seniors-and-Tech-Use_040314.pdf

Zickuhr, K., \& Madden, M. (2012, June 6). Older adults and internet use. Retrieved December 19, 2016, from Pew Internet \& American Life Project: http://www.sainetz.at/dokumente/Older_adults_and_internet_use_2012.pdf 
Dr. Debarati Dhar is currently working as an Assistant Professor in the School of Communications, XIM University, Bhubaneswar, India. She has done her doctoral thesis on New Media and Gerontology. She has been a research fellow at the Centre for Innovative Ageing at Swansea University, Wales, UK (2015) under UGC-UKIERI Thematic Partnership Programme. Dr. Dhar has presented papers in a number of national and international conferences/ seminars and also participated in various national consultation programmes and workshops. She has several publications in reputed journals under her name. She has also been a part of the UGC EpgPathshala Project/ 2017/ under the Ministry of Human Resource and Development, India and has authored 27 modules for Media and Communication Studies. She has also prepared online teaching-learning material for Refresher Programme in Teaching under UGC-HRDC, Jamia Millia Islamia, New Delhi. She has been regularly preparing online learning materials for MOOCs and for IGNOU courses. She has also been a part of several international academic projects. Dr. Dhar has research interest in the areas of New Media and Society, Ageing Studies, Development Communication, Media and Creative Industry. 